\title{
Wandering spleen: A rare entity and a diagnostic dilemma
}

\author{
Ravinder Kaur, Ashish Dua, Ashwani Dalal' \\ Department of Radiodiagnosis and Imaging, 'Department of General Surgery, Government Medical College and Hospital, \\ Chandigarh, India
}

Correspondence: Dr. Ashish Dua, Department of Radiodiagnosis and Imaging, Government Medical College and Hospital, Chandigarh, India.E-mail: drashishdua@gmail.com

\begin{abstract}
Wandering spleen refers to a spleen that is ectopic in its location contrary to a normal spleen which rests in the left hypochondrium. Although it is a rare clinical entity seen in children, it can also be rarely seen in females of reproductive age group. We present one such case of wandering spleen which was misdiagnosed earlier as a sub-hepatic collection.
\end{abstract}

Key words: Rare disease; spleen; wandering

\section{Introduction}

Wandering spleen refers to a spleen that is ectopic in its location contrary to a normal spleen which rests in the left hypochondrium. A normal spleen is kept in place intraperitoneally with the help of gastro-splenic, phreno-colic, colico-splenic, and lieno-renal ligaments and is supplied by the splenic artery and splenic vein. ${ }^{[1-4]}$ This wandering nature of the spleen has been attributed to the laxity of the aforementioned ligaments. Literature has only about 500 documented cases of wandering spleen with a reported incidence of less than $0.5 \% .{ }^{[1]}$ We present a case of wandering spleen which was misdiagnosed earlier as a collection at first glance on ultrasonography (USG).

\section{Case History}

Our patient was a 30-year-old woman who had presented to the medicine OPD for pain abdomen which was radiating to the back for past 3 months and fever on and off for past 2 months. There was also associated loss of appetite and weight

\begin{tabular}{|l|l|}
\hline \multicolumn{2}{|c|}{ Access this article online } \\
\hline Quick Response Code: & \\
\cline { 1 - 2 } & Website: \\
& www.ijri.org \\
& DOI: \\
&
\end{tabular}

for past 1 month. The patient had been taking analgesics for the pain but was not relieved of her symptoms. The local abdominal examination and blood investigations $(\mathrm{Hb}$ and $\mathrm{CBC}$ ) were unremarkable. The patient had a USG abdomen report with her which had been done outside of hospital and had revealed a large heterogeneously hypoechoic collection of approximately size $10 \times 8 \mathrm{~cm}$ in the sub-hepatic region on the right side [Figure 1]. Rest of the abdomen was unremarkable except for the fact that the spleen was not seen in the left hypochondrium. Also, in view of the abdominal pain and mild persistent fever, the patient had undergone a USG guided aspiration of the aforementioned collection outside of hospital which had resulted in a dry tap. Patient subsequently underwent a USG, magnetic resonance imaging (MRI), and computed tomography (CT) angiography of the abdomen at our hospital. The MRI revealed a well-defined lesion of size $10 \times 9 \mathrm{~cm}$ in the sub-hepatic space. It was T1 hypointense with a hyperintense rim and $\mathrm{T} 2$ hyperintense with hypointense septae within [Figure 2]. It showed patchy areas of diffusion restriction along its medial aspect [Figure $3 \mathrm{~A}$ and $\mathrm{B}$ ]. The

This is an open access journal, and articles are distributed under the terms of the Creative Commons Attribution-NonCommercial-ShareAlike 4.0 License, which allows others to remix, tweak, and build upon the work non-commercially, as long as appropriate credit is given and the new creations are licensed under the identical terms.

For reprints contact: WKHLRPMedknow_reprints@wolterskluwer.com

Cite this article as: Kaur R, Dua A, Dalal A. Wandering spleen: A rare entity and a diagnostic dilemma. Indian J Radiol Imaging 2020;30:389-91.

Received: 02-Feb-2020

Accepted: $21-J u n-2020$

Revised: 28-May-2020 Published: $15-$ Oct-2020 


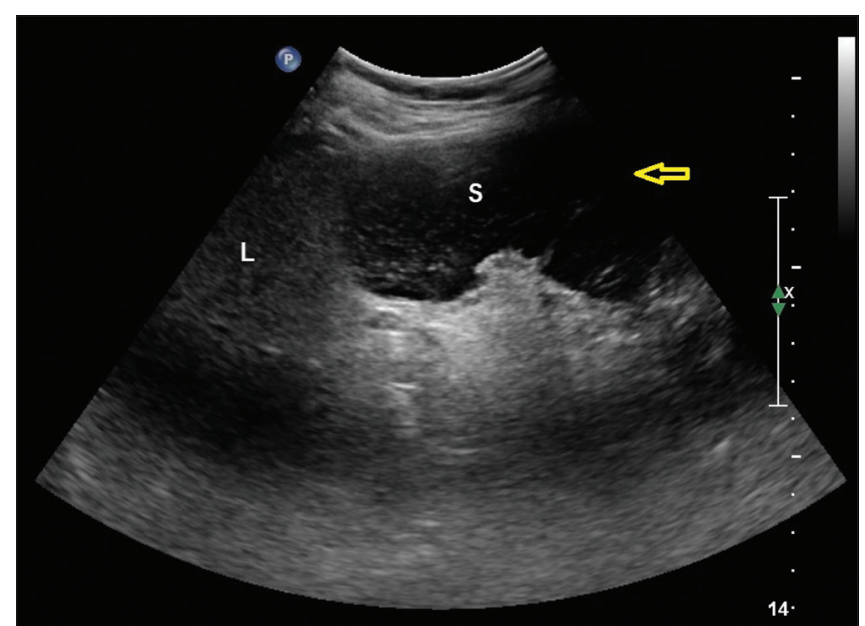

Figure 1: Axial USG image showing a heterogeneously hypoechoic spleen (S) just adjacent to the liver (L) mimicking a sub-hepatic collection

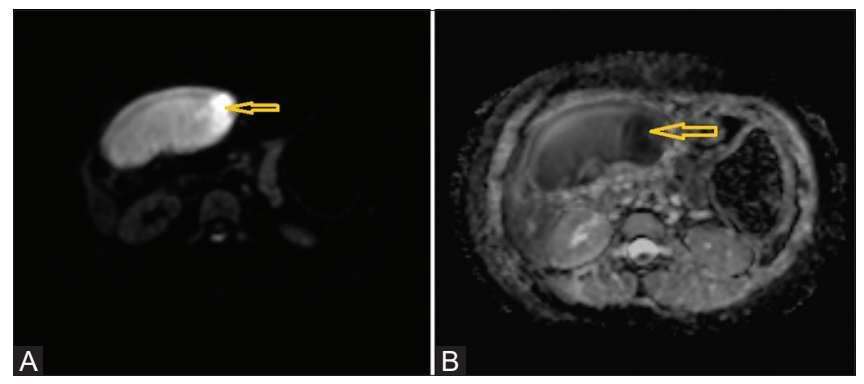

Figure 3 (A and B): (A) DW image in axial plane shows restricted diffusion of viable splenic tissue on medial aspect (Arrow). (B) ADC image in axial plane shows restricted diffusion of viable splenic tissue on medial aspect (Arrow)

spleen was not visualized at its normal anatomical location. A possibility of wandering spleen with infarction was kept. The CT angiography of the abdomen showed the same aforementioned lesion in the sub-hepatic region. It showed peripheral rim enhancement and a small area of homogeneous enhancement along its medial aspect [Figure 4]. Multiple thin hypodense vessels were seen supplying this lesion with some of them showing partial contrast fill-in on arterial and venous phases, likely due to thrombosis [Figure 5]. These findings also suggested wandering spleen with splenic infarct. The patient subsequently got operated. The intra-op findings revealed the spleen was present in the sub-hepatic region and had undergone ischemic infarction due to torsion of the long vascular pedicle. A small part of spleen along its medial aspect was viable and supplied by the collaterals. A total splenectomy was done. The post-op course of patient was uneventful and she was subsequently discharged.

\section{Discussion}

Wandering spleen is a rare clinical entity seen mainly in male infants or women of reproductive age group (20-40 years), in which spleen is present at an ectopic location. ${ }^{[5,6]}$ This has

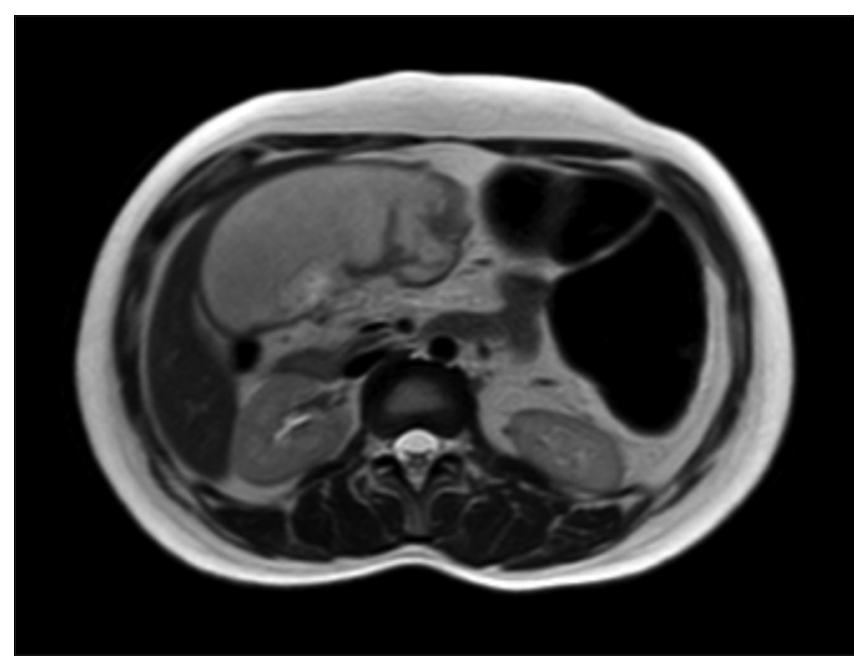

Figure 2: T2W axial image shows hyperintense spleen in subhepatic space

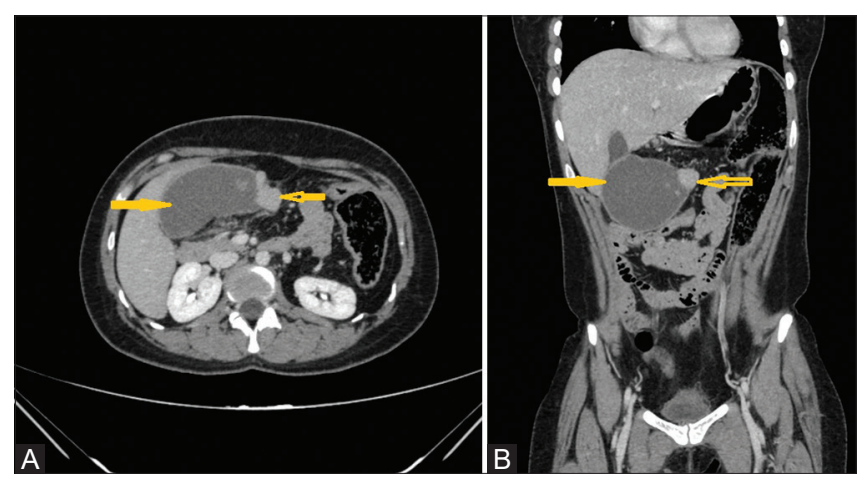

Figure 4 ( $A$ and $B$ ): (A) Axial image showing hypodense predominantly non enhancing spleen (solid arrow) with peripheral rim enhancement. A part of spleen showing enhancement on medial aspect was supplied by mesenteric arteries (Open arrow). (B) Coronal reformatted image showing hypodense predominantly non enhancing spleen (solid arrow) with peripheral rim enhancement. A part of spleen showing enhancement on medial aspect was supplied by mesenteric arteries (Open arrow)

been attributed to the laxity of splenic ligaments which can be congenital or an acquired weakness due to hormonal changes or multiple pregnancies..$^{[7-9]}$ In both the scenarios, the vascular pedicle is long which predisposes it to torsion.

The clinical profile of the patient can range from an asymptomatic presentation to subacute or chronic dull abdominal pain with or without a lump. There can be associated gastrointestinal or urinary tract symptoms due to the external compression because of the ectopic position of the spleen. ${ }^{[10]}$ The main complication seen is torsion of the vascular pedicle which eventually leads to infarction and necrosis of the splenic parenchyma. In such a scenario, patient may also present with acute abdomen which might need immediate surgical intervention. ${ }^{[1]}$

The diagnosis is mostly incidental when a patient undergoes imaging. USG reveals the absence of spleen in the left hypochondrium and is usually seen in the 


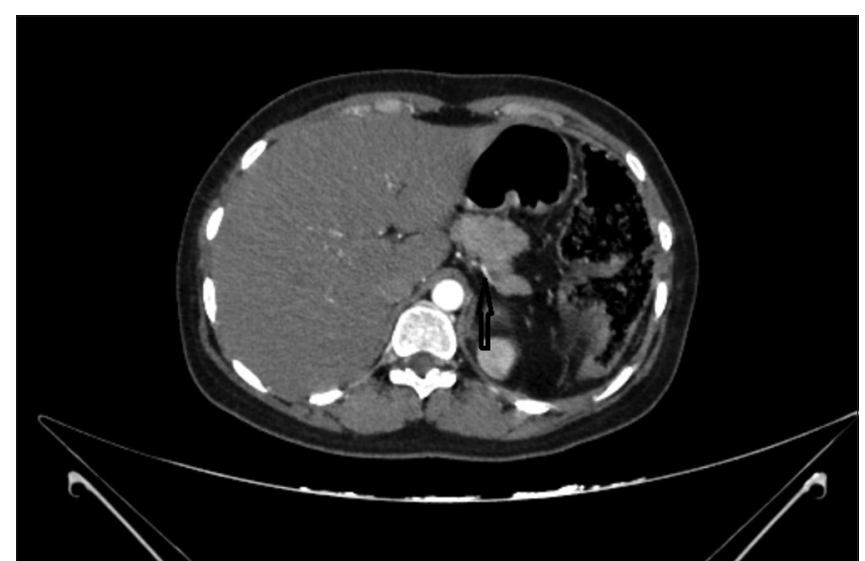

Figure 5: Axial image of CT angiography shows thin proximal splenic artery (Arrow). Distal part of splenic artery was not opacified (not shown here)

abdomen or pelvis. If infarcted or necrosed, it can give the picture of a heterogeneously hypoechoic collection, as was misdiagnosed in our case along with the absence of color flow on doppler imaging. On $\mathrm{CT}$, there is an absence of spleen at the normal anatomic location and an associated abdominal/pelvic mass with a homogenous or heterogeneously hypodense attenuation depending upon the extent of infarction of ectopic spleen. The twisted vascular pedicle in these patients of splenic infarction gives a whorled appearance. ${ }^{[12,13]} \mathrm{CT}$ findings also show lack of contrast fill-in in the splenic vessels in patients with infarcted spleen, s/o thrombosis, as was seen in our patient. ${ }^{[1]}$ MRI also has imaging features similar to $C T$ with presence of spleen at an ectopic location seen on $\mathrm{T} 1 \mathrm{w}$ and $\mathrm{T} 2 \mathrm{w}$ images. The viability of spleen is assessed by the pre and post gadolinium contrast $\mathrm{T} 1 \mathrm{w}$ images. ${ }^{[14]}$

The treatment for such patients is surgical with detorsion and splenopexy. If infarcted, it needs splenectomy followed by vaccination to prevent overwhelming post splenectomy infection (OPSI) ${ }^{[6,9]}$

\section{Conclusion}

The accurate diagnosis of wandering spleen is very difficult owing to its variable presentation. Imaging plays a very important role in the accurate diagnosis of such cases. Treatment of these patients is mainly surgical with detorsion and splenopexy except for patients with splenic infarction and necrosis who require splenectomy.

\section{Declaration of patient consent}

The authors certify that they have obtained all appropriate patient consent forms. In the form the patient(s) has/have given his/her/their consent for his/her/their images and other clinical information to be reported in the journal. The patients understand that their names and initials will not be published and due efforts will be made to conceal their identity, but anonymity cannot be guaranteed.

\section{Financial support and sponsorship}

Nil.

\section{Conflicts of interest}

There are no conflicts of interest.

\section{References}

1. Gayer G, Zissin R, Apter S, Atar E, Portnoy O, Itzchak Y. CT findings in congenital anomalies of the spleen. Br J Radiol 2001;74:767-72.

2. Dodds WJ, Taylor AJ, Erickson SJ, Stewart ET, Lawson TL. Radiologic imaging of splenic anomalies. AJR Am J Roentgenol 1990;155:805-10.

3. Rabushka LS, Kawashima A, Fishman EK. Imaging of the spleen: CT with supplemental MR examination. Radiogr Rev Publ Radiol Soc N Am Inc 1994;14:307-32.

4. Elsayes KM, Narra VR, Mukundan G, Lewis JS, Menias CO, Heiken JP. MR imaging of the spleen: Spectrum of abnormalities. Radiogr Rev Publ Radiol Soc N Am Inc 2005;25:967-82.

5. Sayeed S, Koniaris LG, Kovach SJ, Hirokawa T. Torsion of a wandering spleen. Surgery 2002;132:535-6.

6. Soleimani M, Mehrabi A, Kashfi A, Fonouni H, Büchler MW, Kraus TW. Surgical treatment of patients with wandering spleen: Report of six cases with a review of the literature. Surg Today 2007;37:261-9.

7. Liu H-TM, Lau KK. Wandering spleen: An unusual association with gastric volvulus. AJR Am J Roentgenol 2007;188:W328-330.

8. Chawla S, Boal DKB, Dillon PW, Grenko RT. Splenic torsion. Radiogr Rev Publ Radiol Soc N Am Inc 2003;23:305-8.

9. Stringel G, Soucy P, Mercer S. Torsion of the wandering spleen: Splenectomy or splenopexy. J Pediatr Surg 1982;17:373-5.

10. Misawa T, Yoshida K, Shiba H, Kobayashi S, Yanaga K. Wandering spleen with chronic torsion. Am J Surg 2008;195:504-5.

11. Kapan M, Gümüş M, Önder A, Gümüş H, Aldemir M. A wandering spleen presenting as an acute abdomen: Case report. J Emerg Med 2012;43:e303-305.

12. Ben Ely A, Zissin R, Copel L, Vasserman M, Hertz M, Gottlieb P, et al. The wandering spleen: CT findings and possible pitfalls in diagnosis. Clin Radiol 2006;61:954-8.

13. Swischuk LE, Williams JB, John SD. Torsion of wandering spleen: The whorled appearance of the splenic pedicle on CT. Pediatr Radiol 1993;23:476-7.

14. Deux J-F, Salomon L, Barrier A, Callard P, Bazot M. Acute torsion of wandering spleen: MRI findings. AJR Am J Roentgenol 2004;182:1607-8. 